\title{
Isolation and Characterization of an Entophytic Ethanol Resistant Bacterium from Sap of Saccharum officinarum for Efficient Fermentation
}

\author{
Rukshika Shalani Hewawasam ${ }^{1, \text { ", Sisira Weliwegamage }}{ }^{2}$, Sanath Rajapakse ${ }^{3}$, \\ Subramanium Sotheeswaran ${ }^{2}$ \\ ${ }^{1}$ Post Graduate Institute of Science, University of Peradeniya, Peradeniya, Sri Lanka \\ ${ }^{2}$ College of Chemical Sciences, Institute of Chemistry Ceylon, Rajagiriya, Sri Lanka \\ ${ }^{3}$ Department of Molecular Biology and Biotechnology, Faculty of Science, University of Peradeniya, Sri Lanka
}

Email address:

rukzmck@gmail.com (R. S. Hewawasam)

${ }^{*}$ Corresponding author

\section{To cite this article:}

Rukshika Shalani Hewawasam, Sisira Weliwegamage, Sanath Rajapakse, Subramanium Sotheeswaran. Isolation and Characterization of an Entophytic Ethanol Resistant Bacterium from Sap of Saccharum officinarum for Efficient Fermentation. American Journal of Applied Chemistry. Vol. 7, No. 2, 2019, pp. 42-46. doi: 10.11648/j.ajac.20190702.11

Received: December 23, 2017; Accepted: December 19, 2018; Published: May 9, 2019

\begin{abstract}
Bio fuel is one of the emerging industries around the world due to arise of crisis in petroleum fuel. Fermentation is a cost effective and eco-friendly process in production of bio-fuel. One major problem in microbial ethanol fermentation is the low resistance of conventional microorganisms to the high ethanol concentrations, which ultimately lead to decrease in the efficiency of the process. In the present investigation, an ethanol resistant bacterium was isolated from sap of Saccharum officinarum (sugar cane). The optimal cultural conditions such as, temperature, incubation period, and microbiological characteristics, morphological characteristics, biochemical characteristics, ethanol tolerance, sugar tolerance were investigated. Isolated microorganism was tolerated to $18 \%(\mathrm{~V} / \mathrm{V})$ of ethanol concentration in the medium and $35 \%(\mathrm{~V} / \mathrm{V})$ glucose concentration in the medium. Biochemical characteristics have revealed as Gram negative, non-motile, negative for Indole test, Methyl Red test, Voges- Proskauer`s test, Citrate Utilization test, and Urease test and positive results for Oxidase test. Sucrose, Glucose, Fructose, Maltose, Dextrose, Arabinose, Raffinose, Lactose, and Sachcharose can be utilized by this particular bacterium. It is a significant feature in effective fermentation. The fermentation process was carried out in glucose medium under optimum conditions; temperature $30^{\circ} \mathrm{C}$, and incubated for 72 hours. Maximum ethanol production was recorded as $12.8 \pm 0.4 \%(\mathrm{~V} / \mathrm{V})$. Methanol was not detected throughout the fermentation process. This bacterium is especially useful in biofuel production due to high ethanol tolerance of this microorganism; it can be used to enhance the fermentation process over conventional microorganisms. Investigations are currently conducted on establishing the identity of the bacterium.
\end{abstract}

Keywords: Bacterium, Bio-Fuel, Ethanol Tolerance, Fermentation, Saccharum officinarum

\section{Introduction}

Due to the high demand of petroleum oil, bio-ethanol has emerged as an alternative fuel. It is used in automobiles as an alternative fuel has attracted worldwide attention for its production on a large scale while maintaining the economic status of country [1]. Ethanol production is usually accomplished by chemical synthesis of petroleum substrates and microbial conversion of carbohydrates present in agricultural products [2]. Due to the depletion of petroleum oil and competing industrial needs of petrochemical feed stocks, there is global emphasis in ethanol production by microbial fermentation process [3]. Ethanol production is quite unique on a global perspective. Generally, Saccharomyces cerevisiae is using as the inoculum in fermentation process [4]. In fermentation process, the sugars are converted in to alcohols, carbon dioxide and some by products were produced [5]. Outputs from the ethanol plant include, naturally ethanol, water, stillage, syrup, molasses, 
carbon dioxide, biomass and other alcohols. World largest, leading bio ethanol producers are Brazil and USA [6]. According to Irfan et al., 2014 efficiency of ethanol production is mainly dependent on the choice of microbe strain. Increased yield of ethanol production by microbial fermentation depends on the use of ideal microbial strain, appropriate fermentation substrate, and suitable process technology.

An endophyte is an endosymbiont, often a bacterium, or fungus, which lives within a plant for at least part of its life without causing apparent disease [7]. Endophytic microbes are present in most plant species and can latently or actively colonize the plant locally as well as systemically. It has recently been discovered by Hallman et al, 1997 that these micoorganisms can have beneficial effects on host plants, such as growth promotion and increased resistance against pathogens and parasites.

The isolation and screening of microorganisms from natural sources has always been the most powerful means for obtaining useful and genetically-stable strains for industrially-important products.

Sugar cane (Saccharum officinarum L.) is a tropical and sub-tropical crop that use to produce sugar. Amorim et al., 2004 proclaimed that most of the countries are using sugar cane to produce bio-ethanol. Sugar cane sap is high sugar concentrated material which should be defective medium for microbes [8]. If microbes are survived in this medium, it should be tolerated to high sugar concentration. Some microbes are high sugar tolerated such as Zygosaccharomyces bailii and Zymomonas mobilis. These microbes are inevitable to tolerate high ethanol concentrations as well [9].

Several endophytes in sugar cane has investigated in previous reports. Various parts of sugar cane were attempted such as leaf, root, stalk, and sap for this purpose. The endophytic bacteria isolated from sugarcane (Saccharum spp hybrids) include diazotrophic (nitrogen-fixing) bacteria such as Acetobacter diazotropicus, Herbasprillum and Azospirillum spp [10, 11], and Pseudomonas spp., Zymomonas spp., Burkholderia spp., Bacillus spp., Serratia spp., Klebsiella spp. and Xanthomonas spp as anti-fungal agents [12], Lactic acid bacteria [13] as well.

In present investigation, an unknown microorganism is isolated from sugar cane sap which can tolerate high ethanol concentrations and it is used for fermentation. This study is also an attempt to identify and characterize the bacterial strain by morphological, biochemical, physiological and molecular methods that play an important role in fermentation.

\section{Methodology}

\subsection{Isolation of the Bacterium from Sugar Cane Sap}

Saccharum officinarum (sugar cane) plants were collected from two sugar cane fields (Yakgahapitiya $\left(7^{\circ} 18^{\prime} 0^{\prime \prime}\right.$ North, $80^{\circ} 40^{\prime} 0^{\prime \prime}$ East), Akuregoda (6 $54^{\prime} 0^{\prime \prime}$ North, 79 55' 0" East) in Sri Lanka. Stems $(50 \mathrm{~cm})$ of sugarcane plant (near 6 months old plant) were collected; stems were washed with tap water to remove attached clay. Subsequently, the stems were sterilized with $70 \%$ ethanol, washed with fresh sodium hypochlorite solution for $5 \mathrm{~min}$, rinsed with $70 \%$ ethanol for 30 seconds and finally washed five times with sterile distilled water [14]. Sugarcane stem samples that were not contaminated were used for further analysis.

Samples were cut in to $0.5-\mathrm{cm}$ pieces and macerated with a sterile mortar and pestle; tissue extracts (sugar cane sap) was introduced to a glucose medium (Glucose $80 \mathrm{~g} / \mathrm{L}$, Yeast extract $10 \mathrm{~g} / \mathrm{L}, \quad \mathrm{KH}_{2} \mathrm{PO}_{4} \quad 1 \mathrm{~g} / \mathrm{L}, \quad\left(\mathrm{NH}_{4}\right)_{2} \mathrm{SO}_{4} \quad 1 \mathrm{~g} / \mathrm{L}$, $\mathrm{MgSO}_{4} \cdot 7 \mathrm{H}_{2} \mathrm{O} 0.5 \mathrm{~g} / \mathrm{L}$ ). Culture plate was incubated at $30^{\circ} \mathrm{C}$ for 72 hours. After $48-72 \mathrm{~h}$ incubation, bacteria growing in petri dishes as yellowish white colonies. Cultures were streaked on media to obtain single colonies. Colonies were sub-cultured on the agar-based subculture medium plates by striking technique and re-incubated at $30^{\circ} \mathrm{C}$ for 72 hours. This isolation process carries out in shifts of the agar-based culture medium to the agar-based subculture medium until monocultures were obtained. Monocultures were cultured on the $40 \%(\mathrm{~V} / \mathrm{V})$ of glycerol stocks and incubated at $30^{\circ} \mathrm{C}$ for 72 hours and stored at $-20^{\circ} \mathrm{C}[14]$.

\subsection{Culture Media and Growth Condition}

Different growth media were used to determine the optimum medium for isolate. Nutrient Agar (NA), Luria Agar (LA), YPD (Yeast Extract, Peptone, Dextrose), Yeast Extract Dextrose Chloramphenicol Agar (YDC), glucose medium and Yeast Extract Agar were analyzed to evaluate the optimum growth medium. $25^{\circ} \mathrm{C}, 30^{\circ} \mathrm{C}, 35^{\circ} \mathrm{C}$, and $40^{\circ} \mathrm{C}$ temperatures were used to determine the optimum temperature for growth. 24, 48, 72, 96, 168 hours were used to verify the optimum incubation period.

\subsection{Colony Characteristic and Microscopic Examination ${ }^{4}$}

The characteristics of colony such as size, color, shape, nature, elevation, convex, margin, form, Opacity were presented. Cell morphology of isolate colony was observed by using LEO (LEO 1420VP) Scanning Electron Microscope (SEM). It was operated at an accelerated voltage of $15.00 \mathrm{kV}$ and the current of SE1 at a working distance of about $14 \mathrm{~mm}$. The samples were gold plated by using gold sputter.

\subsection{Screening of Bio Chemical Characteristics}

Gram test, motility test, Indole test [15], Methyl Red test, Voges- Proskauer's test, Citrate Utilization test, Urease test, Oxidase test were analyzed according to standard methods which describe in McClean et al., 1997 and Starch Hydrolyze test and catalase test were analyzed according to MacFadden, 1976. Sucrose, Glucose, Fructose, Maltose, Dextrose, Arabinose, Raffinose, Lactose, and Sachcharose were used to determine the sugar utility test for this isolate bacterium according to Cappuccino and Sherman 1996. 


\subsection{Ethanol Tolerance}

Ethanol Tolerance was determined in isolated bacterium. The bacterium was inoculated in $1 \mathrm{ml}$ of glucose medium which containing different ethanol concentrations $(0,1,3,5$, $9,12,15,18,21 \%)$. Absorbance was measured at $600 \mathrm{~nm}$ after inoculation and subsequently of 1 hour for 6 hours using SpectraMax 384 Molecular Devices, USA [16].

\subsection{Sugar Tolerance}

Sugar Tolerance was determined in isolated bacterium. The bacterium was inoculated in $1 \mathrm{ml}$ of glucose medium which containing different glucose concentrations $(0,10,15$, $20,25,30,35,40,50 \%)$. Absorbance was measured at $600 \mathrm{~nm}$ after inoculation and subsequently of 1 hour for 6 hours using SpectraMax 384 Molecular Devices, USA. [17]

\subsection{Fermentation Process}

The medium used for ethanol fermentation composed of sterilized $100 \mathrm{ml}$ of $35 \%$ glucose solution. After sterilization the medium was allowed to cool at room temperature. After cooling the suspension of $1 \mathrm{ml}$ of bacterial suspension (0.5McFarland) was inoculated into the medium and incubated anaerobically at $30^{\circ} \mathrm{C}$ for 168 hours of fermentation period (Manikandan et al., 2010). Ethanol production was estimated using Gas Chromatography (GC4000/ GL SCIENCES) throughout the fermentation process. [18]

\subsection{Molecular Level Identification}

Total genomic DNA of bacterial strains was extracted by the CTAB method. A universal primer, 16S rRNA gene sequence was to identify this bacterial strain.
Universal primers 27F (5' -AGA GTT TGA TCM TGG CTC AG - 3') and 1492R (5' -CGG TTA CCT TGT TAC GAC TT- 3') were used as forward primer and reverse primer respectively to amplify about $1500 \mathrm{bp}$ fragment of $16 \mathrm{~S}$ rRNA gene according to the procedure described previously [19].

The amplification reaction was performed with initial temperature of $94^{\circ} \mathrm{C}$ for $2 \mathrm{~min}$ followed by 35 cycles consisting of $94^{\circ} \mathrm{C}$ for $1 \mathrm{~min}$; primer annealing at $55^{\circ} \mathrm{C}$ for 1 min and primer extension at $72^{\circ} \mathrm{C}$ for $1 \mathrm{~min}$ and final extension at $72^{\circ} \mathrm{C}$ for $10 \mathrm{~min}$ in a thermal cycler.

Amplified PCR product was sequenced using commercial service of Institute of Institute of Biochemistry, Molecular Biology and Biotechnology, University Of Colombo. The gene sequences were assembled using BioEdit software version 7.1 [20]. The sequence of strain was submitted to National center for biotechnology information (NCBI) Data Bank in order to get an accession number.

The bacterium was identified using complete sequence of 16S rRNA gene on Basic Local Alignment Search Tool (BLAST) search on NCBI servers.

\section{Results and Discussion}

\subsection{Colony Characteristic, Microscopic Examination, and Optimum Growth Conditions}

Yellowish white, small, circular, convex, opaque colonies were obtained in its optimum conditions (temperature $30^{\circ} \mathrm{C}$, incubation period of 72 hours). Cell morphology was obtained as coccos-bacillus and cell arrangement was single (Figure 1). No growth was shown in NA, LA, YDC, Yeast Extract agar. Maximum growth was obtained in YPD and glucose medium.

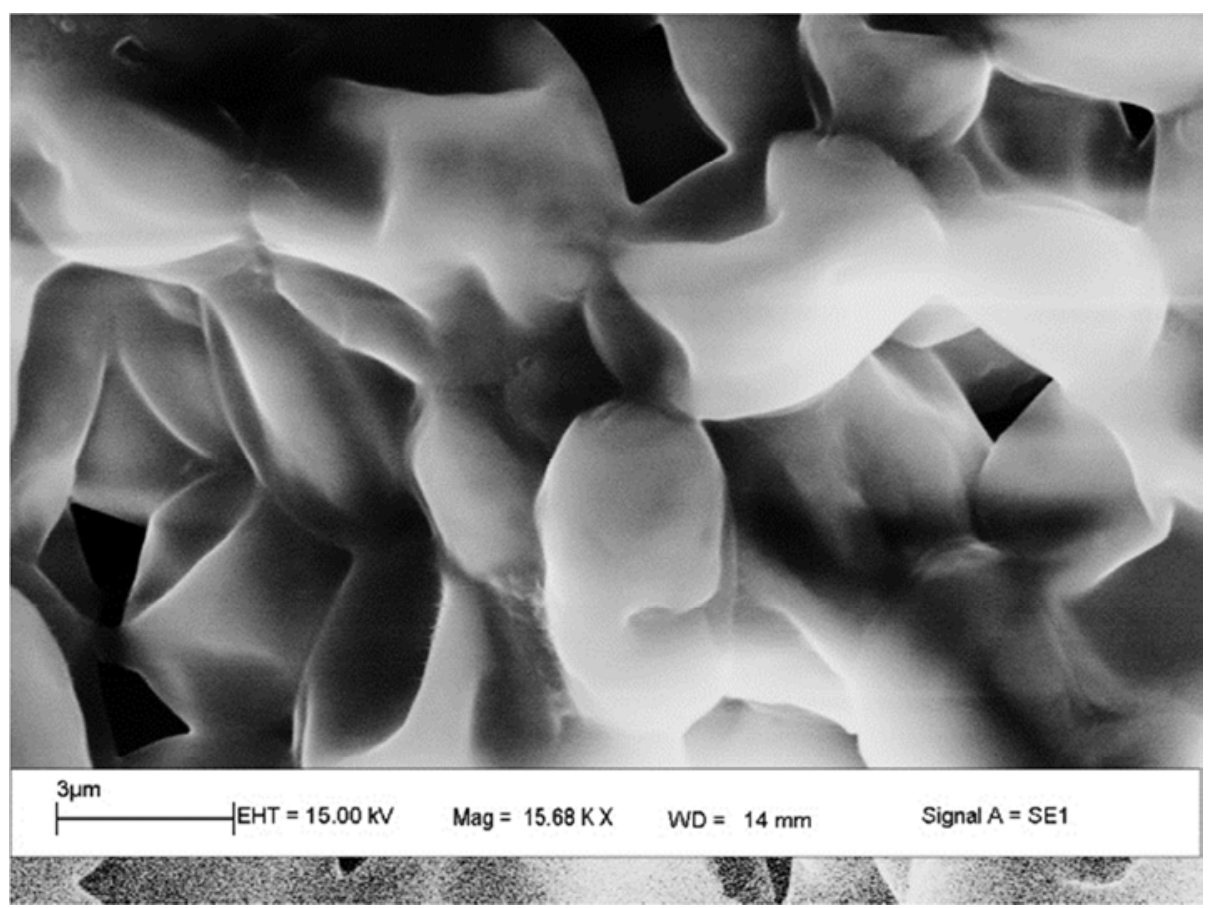

Figure 1. SEM analysis for isolated bacterium under $15.68 \times 10^{3}$ magnification. 


\subsection{Biochemical Characteristics}

Biochemical characteristics have revealed as Gram negative, non-motile, negative for Indole test, Methyl Red test, Voges- Proskauer's test, Citrate Utilization test, catalase test and Urease test. Positive results for Oxidase test was shown by isolated bacterium. Some of sugars such as Sucrose, Glucose, Fructose, Maltose, Dextrose, Arabinose, Raffinose, Lactose and Sachcharose are positive in fermentation process was indicated by color change from red to yellow due to acid production.

\subsection{Ethanol Tolerance}

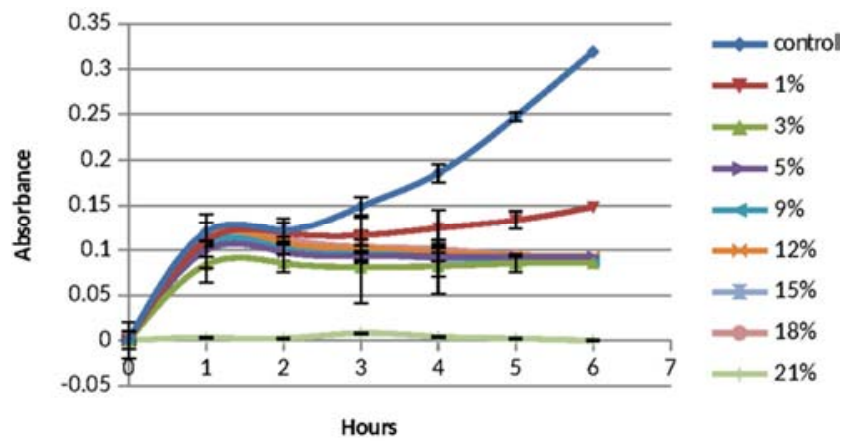

Figure 2. Growth Curve for isolated bacterium in increasing ethanol concentration $(\% V / V)$.

The effect of ethanol concentration on the cell growth and viability of isolated bacterium was analyzed. It tolerates up to $18 \%$ of ethanol in the medium (Figure 2). Conventional microbes such as Saccharomyces cerevisiae does not show that much efficiency in ethanol tolerance. According to that literature Saccharomyces cerevisiae (KY1 and KY3) strains have tolerate up to $15 \%$ of ethanol in the medium. Use of high efficient ethanol tolerant micro-organisms would improve ethanol yield in fermentation and it would direct reduction of distillation costs and hence the profitability of the overall process would be increased. (Chandrasena et al., 2006).

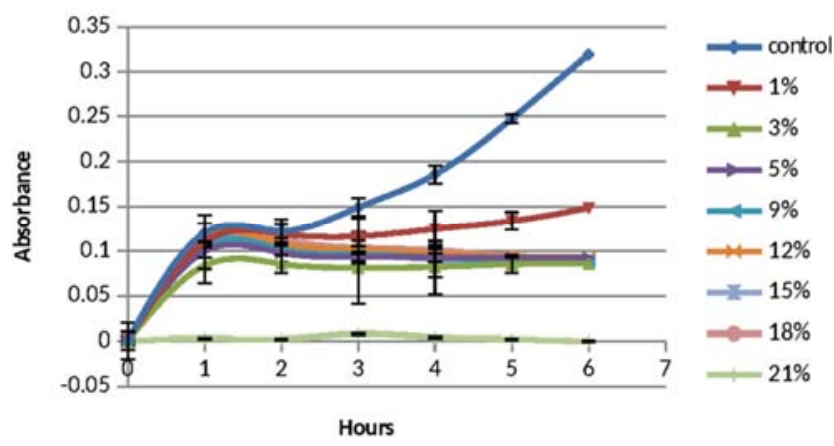

Figure 2. Growth Curve for isolated bacterium in increasing ethanol concentration $(\% V / V)$.

\subsection{Sugar Tolerance}

The effect of sugar concentration on the cell growth and viability of isolated bacterium was analyzed. It tolerates up to
$35 \%$ of sugar in the medium (Figure 3). A conventional microbe such as Saccharomyces cerevisiae does not show that much efficiency and viability in sugar tolerance [16]. The use of high efficiency in sugar tolerance micro-organism is for fermentation must initially high sugar concentrations can be used. Therefore it would enhance the ethanol yield in fermentation process.

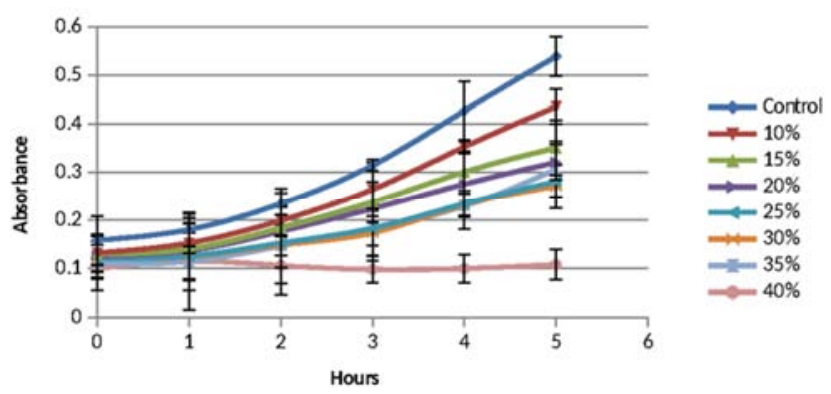

Figure 3. Growth Curve for isolated bacterium in increasing sugar concentration $(\% V / V)$.

\subsection{Fermentation Process}

When using $35 \%$ of initial glucose concentration and $1 \mathrm{ml}$ of $0.5 \mathrm{McFarlend}$ bacterial suspension ethanol concentration was detected by GC. (Figure 4)

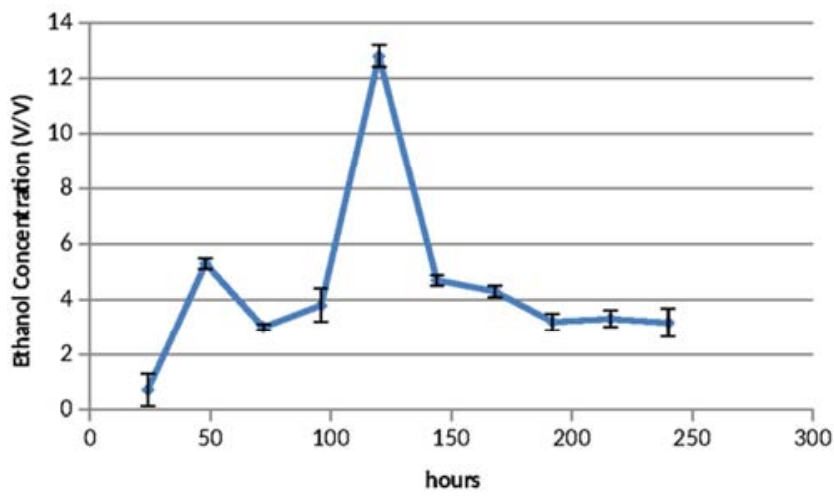

Figure 4. Ethanol concentration variation with time

Highest ethanol concentration as $12.8 \pm 0.4 \%$ (V/V) was obtained from 120 Hours of fermentation. Conventional microbes for fermentation such as Saccharomyces cerevisiae produce lower ethanol concentrations $(7.5 \%$ (V/V) [21]. Comparing to ethanol concentrations isolated bacterium is much more efficient in fermentation. On the other hand in fermentation process methanol was not detected which was indicated the quality of the product.

\subsection{Molecular Level Identification}

Due to high efficiency in ethanol production, identification of the microbe was important.

The sequence analysis was showed less similarity value (96\%) with previously characterized validly published Pseudomonas species. Accession number for 16S rRNA gene of isolated bacterium which obtained from National center 
for biotechnology information is KU056820.

\section{Conclusion}

This ethanol resistant KU056820 can tolerate ethanol up to $18 \%(\mathrm{~V} / \mathrm{V})$ which is significantly ethanol resistant than conventional microbes. Biochemical tests reveal that Sucrose, Glucose, Fructose, Maltose, Dextrose, Arabinose, Raffinose, Lactose and Sachcharose can be utilized by this facultative anaerobic bacterium. Ethanol resistant KU056820 bacterium can tolerate up to $35 \%(\mathrm{~V} / \mathrm{V})$ glucose solution which is remarkable, and it can give higher ethanol yield in fermentation. This is especially useful in bio-fuel production due to high ethanol tolerance of this microorganism; it can be used to enhance the fermentation process over conventional microorganisms.

\section{References}

[1] Shapouri H, Duffield JA, Graboski MS. (1995) Estimating the net energy balance of corn ethanol, U. S. Department of Agriculture, Agricultural Economic Report Number 721.

[2] MacDonald T, Yowell G, McCormack M (2001) US ethanol industry production capacity outlook, California energy commission. Available at: http//www.energy.ca.gov/reports/ 2001-08-29_600-01-017.PDF.

[3] Gruno M, Vaeljamaee P, Pettersson G, Johansson G (2004) Inhibition of the Trichoderma reesei cellulases by cellobiose is strongly dependent on the nature of the substrate. Biotechnol. Bioengin. 86:503-511.

[4] Dorothee B, Monteiro ARDS, Costa MMD, Virkajärvi I, Sacon V, Wilhelmsom A (2014) DesinFix TM 135 in fermentation process for bioethanol production. Brazilian Journal of Microbiology 45, 1, 323-325.

[5] Sasikumar E, Viruthagiri T (2010) Simultaneous Saccharification and Fermentation SSF of Sugarcane Bagasse - Kinetics and Modeling. Int J Chem Biol Engin 32.

[6] CONAB (2012) Acompanhamento de safra brasileira: canadeaçúcar, primeiro levantamento, abril/2012. Conab Brasília.

[7] Backman PA, Sikora RA (2008) Endophytes: An emerging tool for biological control. Biol Cont 46:1-3.

[8] Thaweenut N, Hachisuka Y, Ando S, Yanagisawa S, Yoneyama T (2011) Two season' study on nifH gene expression and nitrogen fixation by diazotrophic endophytes in sugarcane (Saccharum spp. hybrids): expression of nifH genes similar to those of rhizobia. Plant Soil 338:435-449.

[9] Millichip RJ, Doelle HW (1989) Large-scale ethanol production from Milo Sorghum using Zymomonas mobilis. Proc Biochem 24:141-145.
[10] James EK, Olivares FL (1998) Infection and colonization of sugar cane and other graminaceous plants by endophytic diazotrophs. Critical Reviews in Plant Sciences 17, 77-119.

[11] Sevilla M, Burris RH, Gunapala N, Kennedy $\mathrm{C}(2001)$ Comparison of benefit to sugarcane plant growth and $15 \mathrm{~N} 2$ incorporation following inoculation of sterile plants with Acetobacter diazotrophicus wild-type and Nifmutant strains. Molecular Plant Microbe Interactions 14:358-366.

[12] Antwerpen VT, McFarlane SA (2000) The isolation and identification of the causal organism of red stripe symptoms on two sugarcane varieties. 38th Congress of the South African Society for Plant Pathology: 23-28.

[13] Yoganand S, Luximon AB, Jhurry D, Puchooa D (2012) Isolation of lactic acid bacteria from sugar cane juice and production of lactic acid from selected improved strains, Advances in Bioscience and Biotech3:398-407.

[14] Tam HM, Diep CN(2014) Isolation, characterization and identification of endophytic bacteria in sugarcane (Saccharum spp. L.) cultivated on soils of the Dong Nai province, Southeast of Vietnam, American Journal of Life Sciences 2(6): 361-368.

[15] Joseph B, Patra RR, Lawrence R (2007) Characterization of plant growth promoting rhizobacteria associated with chickpea. Int J Plant Prod 1:141-151.

[16] Osho A (2005) Ethanol and Sugar tolerance of wine yeasts isolated from fermenting cashew apple juice, African Journal of Biotechnology 4 (7):660-662.

[17] Ekunsanmi TJ, Odunfa SA (1990) Ethanol tolerance, sugar tolerance and invertase activities of some yeasts strains isolated from steep water of fermenting cassava tubers. $J$. Appl. Bact. 69: 672-675.

[18] Stackler B, Christensen E N (1974) Quantitative determination of ethanol in wine by Gas Chromatography. Am. J. Enol. Vitic. 25, 202-207.

[19] Ahmed I, Yokota A, Fujiwara T (2007) A novel highly boron tolerant bacterium, Bacillus boroniphilus sp. nov., isolated from soil, that requires boron for its growth. Extremophiles $11: 217-224$.

[20] Hall TA (1999) BioEdit: a user-friendly biological sequence alignment editor and analysis program for Windows 95/98/NT. Nucl Acids Symp Ser 41:9-98.

[21] Manikandan T, Umamaheswari M, Jayakumari M, Maheswari K, Subashree M, Mala P, Sevanthi T., (2010) Bioethanol Production from Cellulosic Materials. Asian J. Sci. Technol. 1:5-11. 